\title{
Employing Sterculic Acid - a naturally occurring 1,2-cyclopropene fatty acid - for live-cell imaging of lipids by inverse electron-demand Diels-Alder reaction
}

Kristine Bertheussen ${ }^{1}$, Merel van de Plassche ${ }^{1}$, Thomas Bakkum ${ }^{1}$, Berend Gagestein ${ }^{2}$, lakovia Ttofi ${ }^{2}$, Alexi J.C. Sarris ${ }^{1}$, Herman S. Overkleeft ${ }^{1}$, Mario van der Stelt ${ }^{2 *}$, Sander I. van Kasteren ${ }^{1 *}$

1) Department of Bio-Organic Synthesis, Leiden Institute of Chemistry, Leiden University, Leiden, The Netherlands

2) Department of Molecular Physiology, Leiden Institute of Chemistry, Leiden University, Leiden, The Netherlands

* To whom correspondence should be addressed: s.i.van.kasteren@chem.leidenuniv.nl; m.van.der.stelt@chem.leidenuniv.nl

\begin{abstract}
Bioorthogonal chemistry has allowed the study of biomolecules in living systems with minimal structural perturbations to the molecules under investigation. In the field of lipid research, this has allowed for the study of lipid uptake and processing, whilst minimising artefacts on their biology resulting from pendant detectable groups. To allow the study of unsaturated free fatty acids in live cells, we here report the use of sterculic acid, a 1,2-cyclopropene containing oleic acid analogue, as a bioorthogonal probe. We here show that this lipid can be readily taken up by dendritic cells without toxic side-effects, and that it can subsequently be visualised in live cells using an inverse electrondemand Diels-Alder (IEDDA) reaction with quenched tetrazine fluorophores. Furthermore, this reaction can be integrated into a multiplexed bioorthogonal reaction workflow by combining it with two sequential copper-catalysed Huisgen ligation reactions. This allows for the study of multiple biomolecules in the cell simultaneously by multimodal confocal imaging.
\end{abstract}

\section{Keywords}

Click chemistry, cyclopropene, IEDDA, lipids, sterculic acid

\section{Main Text}

Lipids serve a myriad of roles in biology, as catabolic carbon source ${ }^{[1]}$, as components of cellular and organellar membranes ${ }^{[2]}$, post-translational protein modifications ${ }^{[3]}$, and signalling molecules ${ }^{[4]}$. The study of their contributions in biology is complicated by their lack of direct genetic encoding, their inherent lipophilicity, and the fact that chemical modification, e.g. with pendant fluorophores, can severely alter their structure and biochemical properties. ${ }^{[5]}$

As a result, major efforts have gone into applying bioorthogonal chemistry to the study of lipid biochemistry. By introducing small terminal alkynes and azides in fatty acid tails ${ }^{[6-11]}$, phospholipids ${ }^{[12,13]}$, sphingolipids ${ }^{[14]}$, and cholesterol ${ }^{[15-17]}$, it has been possible to study lipids with only minimal modifications compared to the endogenous molecules. This strategy reduces the chances of the modifications affecting the native function of the lipid, and has successfully been used to study lipid localisation ${ }^{[10,12,13,17]}$, metabolism ${ }^{[11,16]}$, and trafficking ${ }^{[18-20]}$, as well as post-translational lipidation of proteins (reviewed by Distefano and co-worker ${ }^{[21]}$ ). However, the downside of labelling with alkynes/azides has been the lack of availability of live-cell compatible chemistries that can be used with low background reactivity and fast rates. ${ }^{[22,23]}$ Another complicating factor when performing 
bioorthogonal ligation on lipids is imposed by the hydrophobic environment in which the labels reside. Optimising the fluorescent reaction partners, particularly for live-cell imaging, is thus necessary.

In 2008, the groups of Fox and Weissleder reported the inverse electron demand Diels-Alder (IEDDA) reaction - the reaction between an electron-poor diene, such as a tetrazine, and a strained or electronrich dienophile - as a new bioorthogonal reaction. ${ }^{[24,25]}$ This reaction was considered highly favourable for live-cell use, due to its high rates and the fluorescence quenching properties of the tetrazine (reviewed by Bernardes and co-workers ${ }^{[26]}$ ). The most used dienophile, trans-cyclooctene (TCO), is a relatively large modification compared to alkynes or azides ${ }^{[27]}$, but has been used successfully to label, among others, the Golgi-membrane with a TCO-modified ceramide probe. ${ }^{[28,29]}$ However for lipids, where chemical modifications to the structure can largely affect their function, smaller dienophiles were needed. ${ }^{[5,19]}$ An important advance in the application of the IEDDA reaction to live-cell studies of lipid function, was the development of sterically minimal dienophiles. To this end allyl-thiols were reported by Bernardes and co-workers. ${ }^{[30]}$ However, these proved to have rather slow reaction kinetics $\left(\leq 0.002 \mathrm{M}^{-1} \mathrm{~s}^{-1}\right)$. Devaraj and co-workers ${ }^{[31]}$, and Prescher and co-workers ${ }^{[32]}$ simultaneously reported cyclopropenes, so-called MiniTags, as minimal reactive dienophiles ${ }^{[3,34]}$. The cyclopropenes have been incorporated into phospholipids, capable of reacting with rate constants of $13 \mathrm{M}^{-1} \mathrm{~s}^{-1}$ in an IEDDA reaction ${ }^{[31]}$, and are only slightly larger than alkynes and azides ${ }^{[27]}$, making them an attractive alternative to TCO. Cyclopropenes are also reported to have been incorporated into glycans ${ }^{[22,35]}$, and nucleotides ${ }^{[36]}$, combined with live-cell IEDDA reaction and imaging, emphasising their applicability as a bioorthogonal probe.

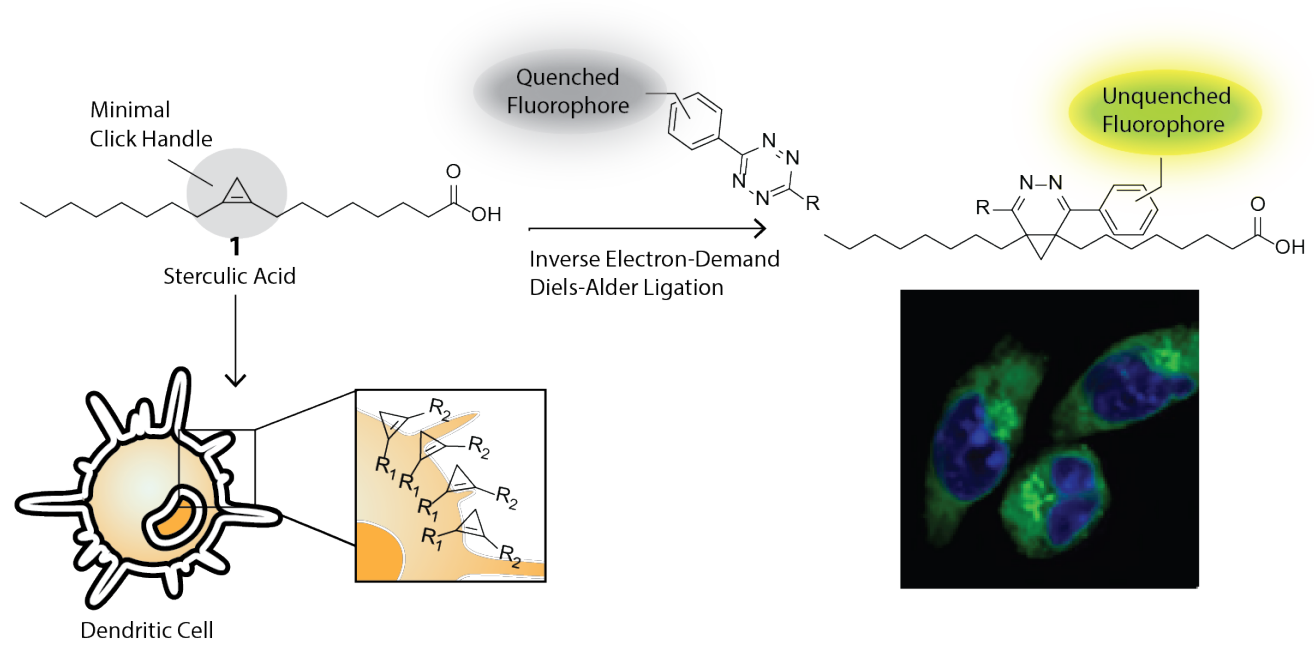

Figure 1: Schematic of the approach to label cells with sterculic acid (1), followed by an IEDDA reaction with tetrazine fluorophores to allow for live-cell confocal imaging, due to fluorophore unquenching upon reaction.

As discussed by Row and Prescher, it is often useful to look to nature for new bioorthogonal probes, as even rare motifs present in natural products indicate stability and compatibility in living systems. ${ }^{[27]}$ In light of this, Nunn's 1952 discovery ${ }^{[37]}$ of the plant metabolite sterculic acid (StA, 1), a carbocylic fatty acid $^{[38]}$ found in the kernels of Sterculia foetida, piqued our interest. This 18-carbon cis-unsaturated lipid contains a naturally occurring 1,2-substituted cyclopropene-ring at C9-C10. In plants, it is synthesised by first addition of a methylene unit to the double bond of oleic acid (18:1, cis-9), followed by enzymatic dehydrogenation to yield the cyclopropene ring. ${ }^{[39]}$ We were curious whether this oleic acid analogue could be used in live-cell compatible labelling chemistry, as it is known to be biologically stable and represents a minimal structural modification of one methylene compared to the parent oleic acid structure. Furthermore, all bioorthogonal IEDDA applications have been explored for 
cyclopropenes with 1,3-, 3,3- or 1,2,3-substitution patterns ${ }^{[31,32,40]}$, whereas there has been no report of a 1,2-substituted cyclopropene as a bioorthogonal probe.

Here, we explore the use of $\mathbf{1}$ as a bioorthogonal reagent, assessing both its ligation kinetics, shortterm toxicity and live- and fixed-cell imaging capacity. We show the fatty acid is taken up readily by dendritic cell lines, and can be used for live-cell microscopy (Figure 1). We furthermore explore the reaction in a multiplexed reaction setup. ${ }^{[4]}$ Multiple groups have previously described that it is possible to combine up to three bioorthogonal ligation reactions in a triple mutually orthogonal system, which allows the tracking of multiple bioorthogonally labelled biomolecules in a single sample. ${ }^{[42-44]}$ We have focussed our efforts in this area in the multiplexing of two copper-catalysed Huisgen ligations $(\mathrm{CCHL}){ }^{[45]}$ We here explore whether the reagent also proved compatible with the copper-catalysed Huisgen ligation ( $\mathrm{CCHL}$ ), allowing us to perform a triple-click reaction. These experiments all indicate that $\mathbf{1}$ is a valuable reagent to study fatty acid uptake in cells.

To assess whether 1 could be used in a live-cell IEDDA reaction, we designed and synthesised a small library of tetrazine-containing turn-on fluorophores for optimisation of the reaction (Scheme 1). Tetrazines have a broad absorption spectrum, which peaks around $515 \mathrm{~nm}$, meaning it can efficiently quench fluorescent dyes of wavelengths $\leq 550 \mathrm{~nm}$ via fluorescence resonance energy transfer (FRET). ${ }^{[46]}$ Therefore, tetrazine fluorophores are so-called turn-on fluorophores, where their fluorescent intensity increases upon ligation, and their reaction with 1 can be readily quantified. We selected two different green fluorophores, BODIPY and Alexa Fluor 488 (AF488), and ligated these to three differently substituted tetrazines ( $\mathrm{H}-$, methyl- or pyridyl-substituted). Additionally, we attached the tetrazines to the BODIPY core at two different distances, as previous research has shown that decreasing the distance between the fluorophore and the tetrazine can improve the quenching effect. ${ }^{[47,48]}$

Tetrazines 3-5 were synthesised according to a literature procedure. ${ }^{[49]}$ The free amine of 4(aminomethyl) benzonitrile was protected using di-tert-butyl dicarbonate and DIPEA to yield precursor 2. This compound was converted into $N$-Boc-protected aminoalkyltetrazines 3-5 by a Lewis acid catalysed condensation of nitriles with hydrazine, followed by oxidation with sodium nitrite under acidic conditions. The protected amine of tetrazine 3-5 was deprotected using $\mathrm{HCl} /$ dioxane and immediately coupled to the commercially available AF488 and BODIPY-FL via an NHS coupling, resulting in tetrazine fluorophores 6-11.

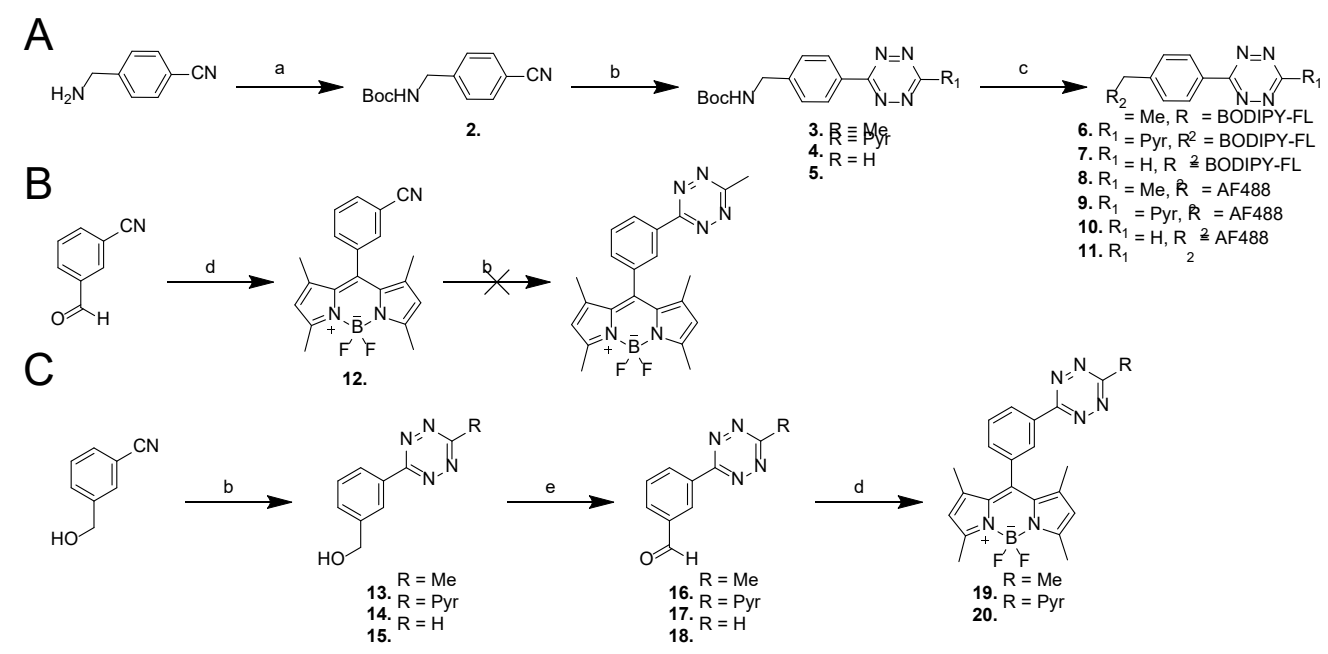

Scheme 1: The synthesis of the tetrazine fluorophores 6-11 and 19-20. a) $\mathrm{Boc}_{2} \mathrm{O}, \mathrm{NaOH}, \mathrm{H}_{2} \mathrm{O}$. b) (1) $\mathrm{NH}_{2} \mathrm{NH}_{2}$, $\mathrm{Zn}(\mathrm{OTf})_{2}$, acetonitrile/ 2-cyanopyridine or formamidine acetate. (2) $\mathrm{NaNO}_{2}$ in DCM/AcOH (1:1, v:v). c) (1) $4 \mathrm{M} \mathrm{HCl}$, dioxane/DCM (1:1, v/v) (2) AF488-NHS or BODIPY-FL NHS, DIPEA, DCM. d) (1) 2,4-Dimethylpyrrole, TFA. (2) DDQ. (3) TEA, BF3.OEt2. (e) DMP, DCM. 
For the other BODIPY tetrazines, we first followed the synthesis previously published by Weissleder and co-workers. ${ }^{[48]}$ However, we found that the conditions needed to form a tetrazine on precursor 12 were too harsh for the BODIPY core, and only a trace amount of product was formed. To circumvent this issue, we first synthesised tetrazines 13-15 starting from commercially available 3-cyanobenzyl alcohol. ${ }^{[50]}$ Each respective tetrazine alcohol was then oxidised into an aldehyde using Dess-Martin periodinane, resulting in tetrazine 16-18. To form BODIPY 19 and 20, tetrazines 16 and 17 were reacted with 2,4-dimethylpyrrole to form the dipyrromethene precursors, which were subsequently oxidised using DDQ and reacted in a chelation reaction with boron trifluoride. Unfortunately, tetrazine 18 proved too unstable to withstand the BODIPY formation.

To investigate the fluorescence turn-on of our synthesised fluorophores upon reaction with 1 , the fluorophores were incubated with 1 in either PBS, DMSO/ $\mathrm{H}_{2} \mathrm{O}(1: 1, \mathrm{v} / \mathrm{v})$ or complete RPMI 1640 medium augmented with $10 \%$ fetal calf serum, and the fluorescent signal measured over time (Figures 2 and S1). In line with previous reports, the two BODIPY tetrazines 19 and 20 showed the highest turnon ratio in PBS, followed by BODIPY FL tetrazines 6-7. ${ }^{[47,48]}$ It was also found that pyridyl-substituted tetrazines $\mathbf{7}$ and $\mathbf{2 0}$ reacted faster than methyl-substituted tetrazines $\mathbf{6}$ and 19, as reported by the Hilderbrand group. ${ }^{[51]}$ It was not possible to determine the relative reaction rate of H-substituted tetrazines $\mathbf{8}$ and 11, as they show almost no turn-on in PBS. Some loss of fluorescence, likely due to photobleaching, was also observed for 19 and 20. In DMSO/ $\mathrm{H}_{2} \mathrm{O}$ or complete medium little-to-no turnon was observed for all the fluorophores (Figure S1).

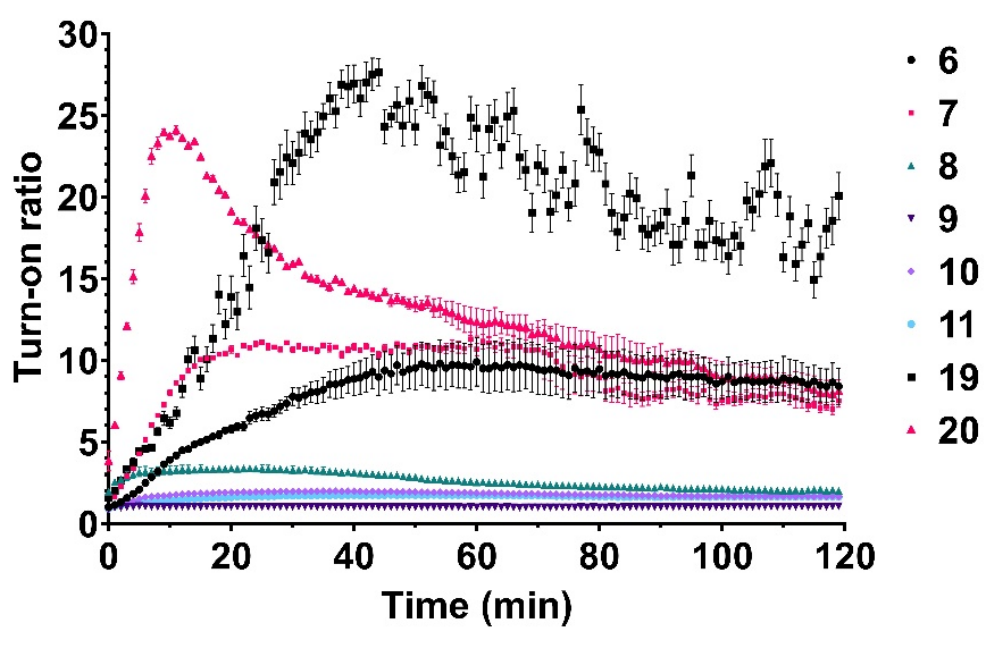

Figure 2: Turn-on ratio of tetrazine fluorophores 6-11 and 19-20 upon reaction with 1 in $\mathrm{PBS}$ at $25^{\circ} \mathrm{C}$.

Due to the capricious turn-on behaviour in medium and $\mathrm{DMSO} / \mathrm{H}_{2} \mathrm{O}$, we opted to assess them all for the live-cell imaging of 1 (Figure S2). In contrast to cell-free medium results, 6-8 and 19-20 exhibited successful ligation after uptake of 1 by DC2.4 dendritic cells ${ }^{[52]}$. This cell line was chosen due to its excellent imaging properties and our previous experience in using it as a good in vitro model cell line for optimising bioorthogonal chemistry to study dendritic cell biology. ${ }^{[33]}$ The Alexa Fluor-based dyes 9-11 were unable to react with 1 in live cells. This is probably due to the hydrophilic nature of these fluorophores not allowing them to diffuse over the hydrophobic plasma membrane. Fluorophore 19 showed the brightest labelling with the lowest background fluorescence, allowing for imaging at lower laser intensities. As this leads to less bleaching of the sample, $\mathbf{1 9}$ was deemed to be the best fluorophore for live-cell imaging (Figure 3A). For the brightness of the labelling in live cells, it appears to not make a difference which substituent is on the tetrazine core, and either $\mathrm{H}-$, methyl- or pyridylsubstituted tetrazines work equally well. As well as being dependent on fluorophore structure, the 
labelling of $\mathbf{1}$ in live cells is also dependent on fluorophore concentration in a dose-dependent manner, and on fluorophore incubation time (Figures S3 and S4).
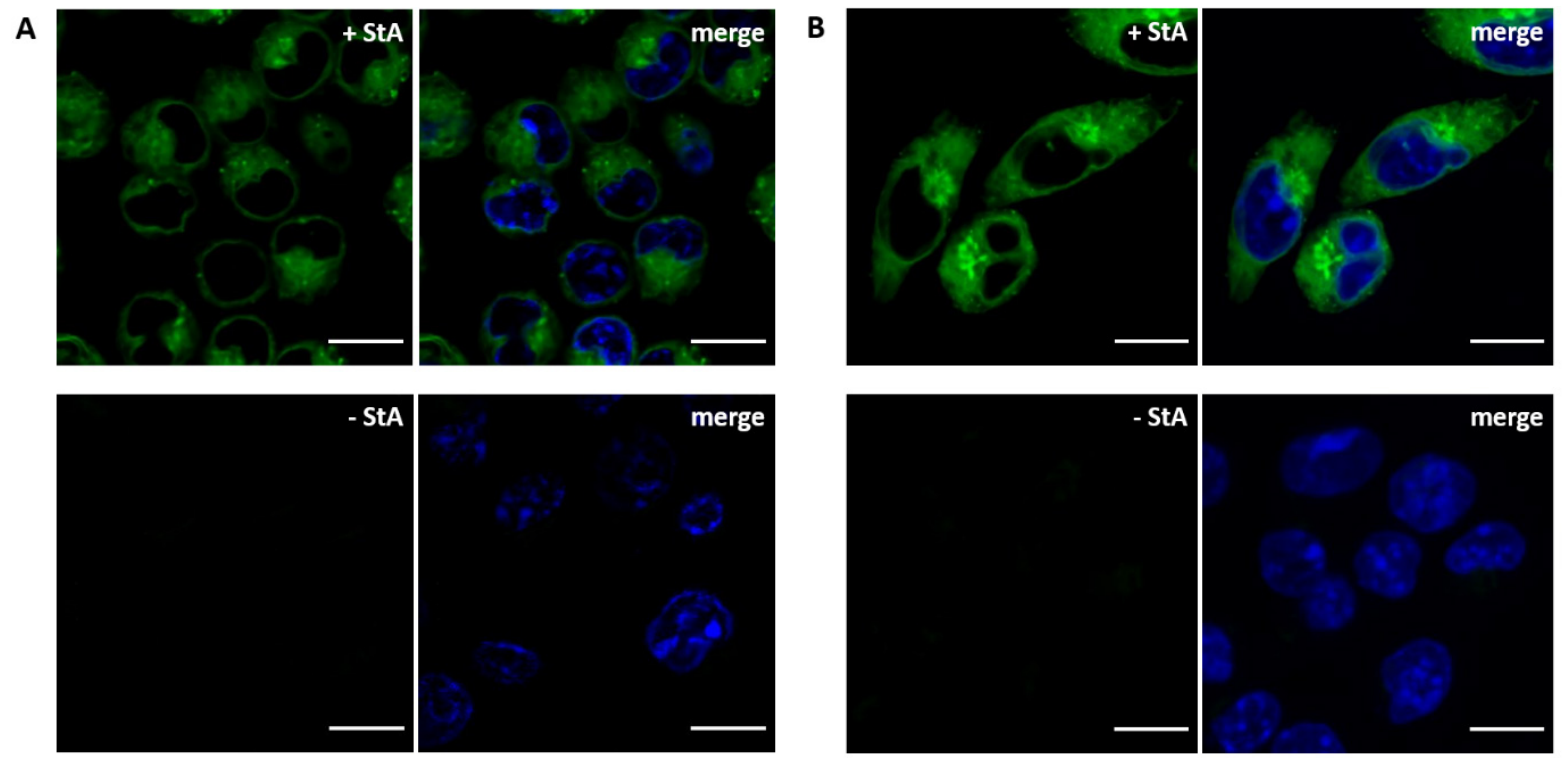

Figure 3: Confocal imaging of the best fluorophores to label $\mathbf{1}(+\mathrm{StA})$ in live (A) or fixed (B) DC2.4 cells, as well as cells incubated without the probe (-StA). (A) Live-cell imaging showing a single slice of labelled cells visualised with 19. (B) Maximum intensity projection of fixed and permeabilised cells visualised with 8. DNA was counterstained with Hoechst 33342 (blue) for reference. All scale bars represent $10 \mu \mathrm{m}$.

To evaluate whether $\mathbf{1}$ was also able to react with tetrazine fluorophores in fixed cells, we tested the fluorophore library on fixed and permeabilised cells (Figure S5). Consistent with the results found in live cells, fluorophores 6-8 were able to visualise the localisation of $\mathbf{1}$. As opposed to the live-cell imaging, 9-11 showed labelling in fixed and permeabilised cells. However, the intensity of the signal of $\mathbf{9}$ and $\mathbf{1 0}$ was too low to be detected at the same laser settings as 6-8. Upon increasing the laser intensity, these fluorophores also showed signal over background (Figure S6). The signals of $\mathbf{1 9}$ and $\mathbf{2 0}$ were the brightest of the library, but showed oversaturated spots in fixed cells, which could originate from precipitation of the fluorophores under the reaction conditions. Fluorophore $\mathbf{8}$ was deemed to be the best alternative for fixed cells, due to its bright and consistent labelling (Figure 3B). A general trend seen from our tetrazine library in fixed cells is that the $\mathrm{H}$-substituted tetrazines give the brightest signal, followed by the pyridyl tetrazines.

In both live and fixed cells (Figure 3), the localisation of $\mathbf{1}$ can be observed throughout the cells, except for within the nucleus. As exogenous free fatty acids can be readily incorporated into phopsholipids and other lipids via an acyl coenzyme $A$ intermediate ${ }^{[54]}$, this would suggest that labelling of organellar membranes also occur. This is in keeping with 1 serving as a mimic for oleic acid, which is known to be found ubiquitously in membrane lipids. ${ }^{[55]}$ In fixed cells (Figure 3B), which are displayed as maximum intensity projections, it is also apparent that the fluorescent signal appears to be stronger in the endoplasmic reticulum (ER). This can be explained by incorporation of the free fatty acids into phospholipids through Lands' cycle and the Kennedy pathway, which occurs mainly at the ER. ${ }^{[56]}$

Comparisons between the turn-on study (Figure 2) and microscopy (Figures S2 and S5) show that the in vitro results cannot be consistently translated to the cell experiments. For both live- and fixed-cell imaging fluorophore $\mathbf{8}$ gave a bright and clear signal over background, and was even deemed the best fluorophore for fixed-cell imaging, whereas it showed almost no turn-on in vitro in PBS. This discrepancy accentuates the importance of studying bioorthogonal reactions in complex systems. 
Multiplexing of bioorthogonal reactions is growing in popularity, meaning more complex systems can be studied simultaneously. ${ }^{[57]}$ We have previously shown that two copper-catalyzed Huisgen reactions can be combined in the same sample. ${ }^{[45]}$ Here, we wanted to explore whether the sterculic acid ligation could be included in this workflow, allowing three biomolecules to be simultaneously visualised by multimodal fluorescent imaging. DC2.4 cells were metabolically labelled with the alkyne-containing thymidine analogue 5-ethynyl-2'-deoxyuridine $(\mathrm{EdU})^{[58]}$, the azide-containing palmitic acid analogue 15-azidopentadecanoic acid (azido palmitic acid, azPA) and 1, after which the cells were fixed before performing the corresponding bioorthogonal reactions with AZDye ${ }^{\mathrm{TM}}$ 555-azide, AZDye ${ }^{\mathrm{TM}}$ 647-alkyne and compound $\mathbf{7}$, respectively (Figure 4).

Figures 4 and S7 show that the triple bioorthogonal labelling strategy worked well, with good signalto-noise ratios for all three click reactions, indicating that $\mathbf{1}$ does not have detectable cross-reactivity with the CCHL components. This means that 1 can be used in combination with other click chemistries, allowing for the simultaneous study of multiple biomolecules. In addition, the chemical synthesis of 1 from its precursor stearolic acid via a Simmons-Smith reaction has previously been reported ${ }^{[59]}$, and stearolic acid can in turn be synthesised from oleic acid via bromination-dehydrobromination. ${ }^{[60]}$ This opens the door for the synthesis of cyclopropene analogues of other monounsaturated fatty acids, and their subsequent study by the IEDDA bioorthogonal reaction.

1 is reported to be an inhibitor of the enzyme stearoyl-CoA desaturase 1 (SCD1) which catalyses the transformation of saturated fatty acids such as stearic or palmitic acid to their monounsaturated counterparts oleic or palmitoleic acid, respectively. ${ }^{[61]}$ Lowered activity of SCD1 has been linked to various cellular responses such as ER stress, autophagy, and apoptosis ${ }^{[11]}$, which in turn poses the question if the addition of 1 would be toxic to the cells by its inhibiting effect on SCD1. To ensure that this was not the case, we incubated DC2.4 cells with a concentration range of 1 and measured cell viability after $24 \mathrm{~h}$ by 3-(4,5-dimethylthiazol-2-yl)-2,5-diphenyltetrazolium bromide (MTT) assay (Figure S8). No decrease of DC2.4 cell viability was observed for concentrations of 1 up to $50 \mu \mathrm{M}$ and at higher concentrations there was no difference with vehicle-induced toxicity. Nevertheless, inhibition of SCD1 should be taken into account in future use of cyclopropene-modified lipids. 
A
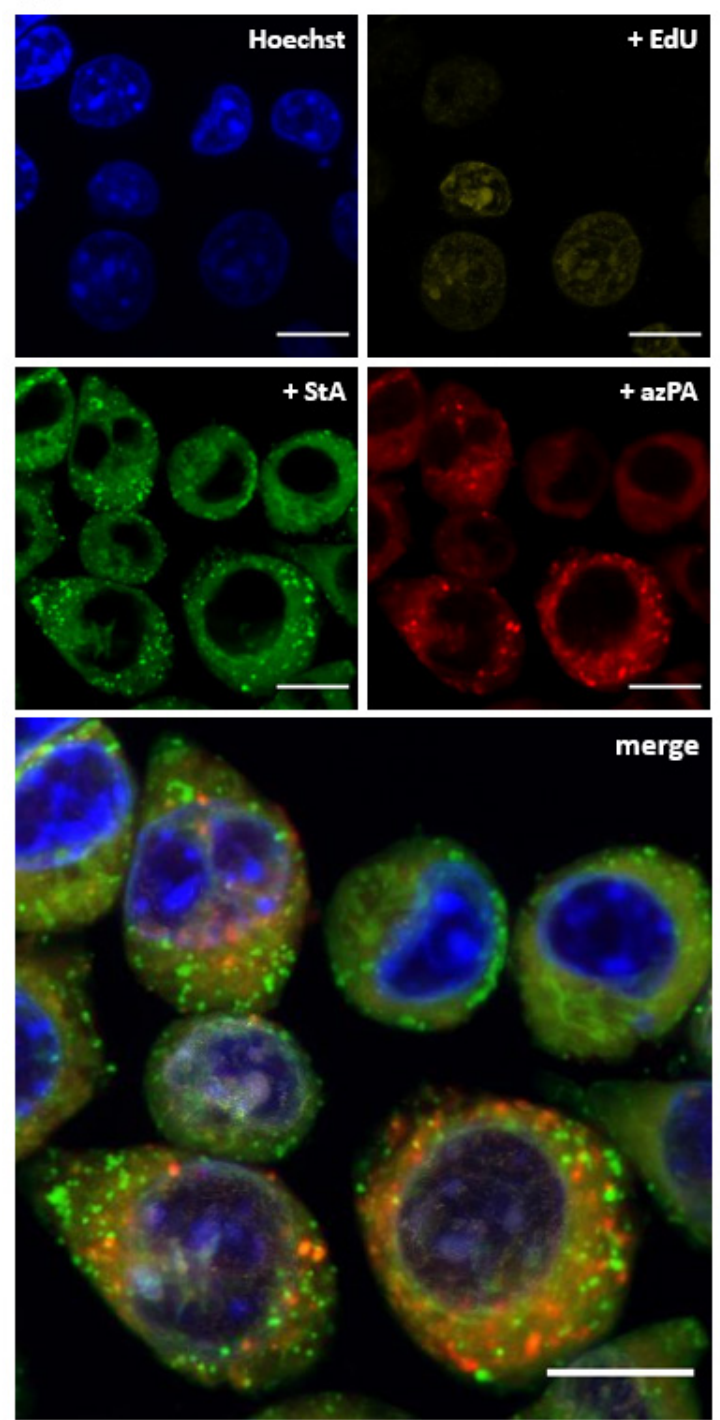

B
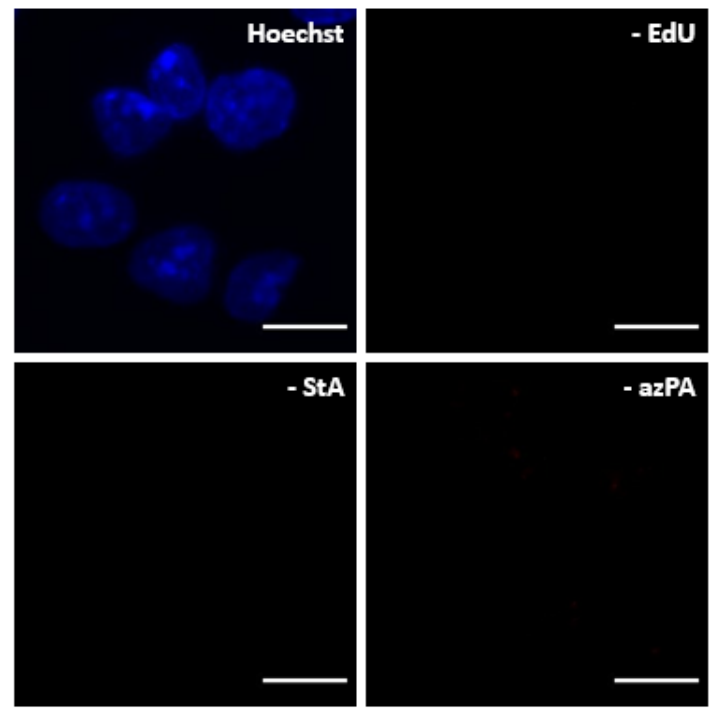

- azPA

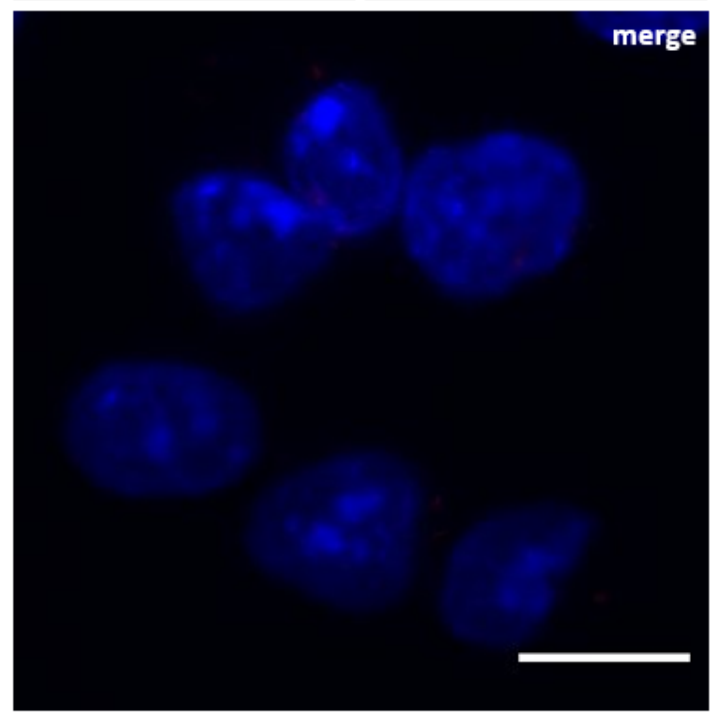

Figure 4: Maximum intensity projections showing triple bioorthogonal labelling of DC2.4 cells incubated with (A) 5-ethynyl-2'deoxyuridine (EdU, yellow) for 20h, followed by 1 (StA, green) and azido palmitic acid (azPA, red) simultaneously for $1 \mathrm{~h}$. The probes were visualised with AZDye ${ }^{\mathrm{TM}}$ 555-azide, compound 7, and AZDye ${ }^{\mathrm{TM}}$ 647alkyne, respectively. (B) The cells were incubated without probes and treated in the same triple-click manner as described above to show the background signal. DNA was counterstained with Hoechst 33342 (blue) for reference. All scale bars represent $10 \mu \mathrm{m}$.

Here we have reported the first use of sterculic acid, a non-toxic 1,2-substituted cyclopropenecontaining fatty acid, for studying lipids in both live and fixed cells. The cyclopropene moiety readily reacts with tetrazines, allowing the study of fatty acid localisation by confocal microscopy. This reaction can occur in a mutually orthogonal manner with two subsequent CCHL reactions, allowing the study of multiple biomolecules simultaneously. The use of sterculic acid, combined with a reported generally applicable synthesis of cyclopropene-containing fatty acids, means that lipids can now be visualised using live-cell microscopy; a sorely needed addition to the available tools for these elusive biomolecules. 


\section{Acknowledgements}

We would like to acknowledge Ken Rock for his kind gift of the DC2.4 cell line. We would also kindly like to thank the Institute for Chemical Immunology (NWO-Zwaartekracht Grant) and the European Research Council (ERC-CoG 865175) for funding the work described here.

\section{References}

[1] S. M. Houten, R. J. A. Wanders, J. Inherit. Metab. Dis. 2010, 33, 469-477.

[2] G. van Meer, D. R. Voelker, G. W. Feigenson, Nat. Rev. Mol. Cell Biol. 2008, 9, 112-124.

[3] M. D. Resh, Prog. Lipid Res. 2016, 63, 120-131.

[4] M. P. Wymann, R. Schneiter, Nat. Rev. Mol. Cell Biol. 2008, 9, 162-176.

[5] T. W. Bumpus, J. M. Baskin, Trends Biochem. Sci. 2018, 43, 970-983.

[6] A. L. Ticho, P. Malhotra, C. R. Manzella, P. K. Dudeja, S. Saksena, R. K. Gill, W. A. Alrefai, J. Biol. Chem. 2020, 295, 4488-4497.

[7] E. Thinon, A. Percher, H. C. Hang, ChemBioChem 2016, 17, 1800-1803.

[8] A. J. Pérez, H. B. Bode, J. Lipid Res. 2014, 55, 1897-1901.

[9] M. A. Kostiuk, M. M. Corvi, B. O. Keller, G. Plummer, J. A. Prescher, M. J. Hangauer, C. R. Bertozzi, G. Rajaiah, J. R. Falck, L. G. Berthiaume, FASEB J. 2008, 22, 721-732.

[10] G. Charron, M. M. Zhang, J. S. Yount, J. Wilson, A. S. Raghavan, E. Shamir, H. C. Hang, J. Am. Chem. Soc. 2009, 131, 4967-4975.

[11] C. Thiele, C. Papan, D. Hoelper, K. Kusserow, A. Gaebler, M. Schoene, K. Piotrowitz, D. Lohmann, J. Spandl, A. Stevanovic, A. Shevchenko, L. Kuerschner, ACS Chem. Biol. 2012, 7, 2004-2011.

[12] C. Y. Jao, M. Roth, R. Welti, A. Salic, Proc. Natl. Acad. Sci. 2009, 106, 15332 LP - 15337.

[13] C. Y. Jao, M. Roth, R. Welti, A. Salic, ChemBioChem 2015, 16, 472-476.

[14] M. Garrido, J. L. Abad, G. Fabriàs, J. Casas, A. Delgado, ChemBioChem 2015, 16, 641-650.

[15] C. Y. Jao, D. Nedelcu, L. V Lopez, T. N. Samarakoon, R. Welti, A. Salic, ChemBioChem 2015, 16, 611-617.

[16] K. Hofmann, C. Thiele, H. F. Schö̈t, A. Gaebler, M. Schoene, Y. Kiver, S. Friedrichs, D. Lü̈johann, L. Kuerschner, J. Lipid Res. 2014, 55, 583-591.

[17] L. Rakers, D. Grill, A. L. L. Matos, S. Wulff, D. Wang, J. Börgel, M. Körsgen, H. F. Arlinghaus, H.-J. Galla, V. Gerke, F. Glorius, Cell Chem. Biol. 2018, 25, 952-961.e12.

[18] H. C. Hang, J. P. Wilson, G. Charron, Acc. Chem. Res. 2011, 44, 699-708.

[19] D. Liang, K. Wu, R. Tei, T. W. Bumpus, J. Ye, J. M. Baskin, Proc. Natl. Acad. Sci. 2019, 116, 15453 LP 15462.

[20] A. J. Pérez, H. B. Bode, ChemBioChem 2015, 16, 1588-1591.

[21] K. F. Suazo, K.-Y. Park, M. D. Distefano, Chem. Rev. 2021, 121, 7178-7248.

[22] V. Rigolot, C. Biot, C. Lion, Angew. Chemie Int. Ed. 2021, 60, 23084-23105.

[23] R. van Geel, G. J. M. Pruijn, F. L. van Delft, W. C. Boelens, Bioconjug. Chem. 2012, 23, 392-398.

[24] M. L. Blackman, M. Royzen, J. M. Fox, J. Am. Chem. Soc. 2008, 130, 13518-13519.

[25] N. K. Devaraj, R. Weissleder, S. A. Hilderbrand, Bioconjug. Chem. 2008, 19, 2297-2299. 
[26] B. L. Oliveira, Z. Guo, G. J. L. Bernardes, Chem. Soc. Rev. 2017, 46, 4895-4950.

[27] R. D. Row, J. A. Prescher, Acc. Chem. Res. 2018, 51, 1073-1081.

[28] R. S. Erdmann, H. Takakura, A. D. Thompson, F. Rivera-Molina, E. S. Allgeyer, J. Bewersdorf, D. Toomre, A. Schepartz, Angew. Chemie Int. Ed. 2014, 53, 10242-10246.

[29] R. S. Erdmann, D. Toomre, A. Schepartz, in (Ed.: H. Erfle), Springer New York, New York, NY, 2017, pp. 65-78.

[30] B. L. Oliveira, Z. Guo, O. Boutureira, A. Guerreiro, G. Jiménez-Osés, G. J. L. Bernardes, Angew. Chemie Int. Ed. 2016, 55, 14683-14687.

[31] J. Yang, J. Šečkutė, C. M. Cole, N. K. Devaraj, Angew. Chemie Int. Ed. 2012, 51, 7476-7479.

[32] D. M. Patterson, L. A. Nazarova, B. Xie, D. N. Kamber, J. A. Prescher, J. Am. Chem. Soc. 2012, 134, 18638-18643.

[33] J. Sauer, G. Heinrichs, Tetrahedron Lett. 1966, 7, 4979-4984.

[34] P. Dowd, A. Gold, Tetrahedron Lett. 1969, 10, 85-86.

[35] C. M. Cole, J. Yang, J. Šečkutè, N. K. Devaraj, ChemBioChem 2013, 14, 205-208.

[36] J. Šečkutè, J. Yang, N. K. Devaraj, Nucleic Acids Res. 2013, 41, e148-e148.

[37] J. R. Nunn, J. Chem. Soc. 1952, 313-318.

[38] M. U. Ahmad, S. M. Ali, A. Ahmad, S. Sheikh, I. Ahmad, in (Ed.: M.U.B.T.-F.A. Ahmad), AOCS Press, 2017, pp. 147-185.

[39] A. Greenberg, J. Harris, J. Chem. Educ. 1982, 59, 539.

[40] P. Kumar, T. Jiang, O. Zainul, A. N. Preston, S. Li, J. D. Farr, P. Suri, S. T. Laughlin, Tetrahedron Lett. 2018, 59, 3435-3438.

[41] Y. Hu, J. M. Schomaker, ChemBioChem 2021, 22, 3254-3262.

[42] L. I. Willems, N. Li, B. I. Florea, M. Ruben, G. A. van der Marel, H. S. Overkleeft, Angew. Chemie Int. Ed. 2012, 51, 4431-4434.

[43] C. Simon, C. Lion, C. Spriet, F. Baldacci-Cresp, S. Hawkins, C. Biot, Angew. Chemie Int. Ed. 2018, 57, 16665-16671.

[44] T. I. Chio, H. Gu, K. Mukherjee, L. N. Tumey, S. L. Bane, Bioconjug. Chem. 2019, 30, 1554-1564.

[45] T. Bakkum, M. T. Heemskerk, E. Bos, M. Groenewold, N. Oikonomeas-Koppasis, K. V Walburg, S. van Veen, M. J. C. van der Lienden, T. van Leeuwen, M. C. Haks, T. H. M. Ottenhoff, A. J. Koster, S. I. van Kasteren, ACS Cent. Sci. 2020, 6, 1997-2007.

[46] G. Beliu, A. J. Kurz, A. C. Kuhlemann, L. Behringer-Pliess, M. Meub, N. Wolf, J. Seibel, Z.-D. Shi, M. Schnermann, J. B. Grimm, L. D. Lavis, S. Doose, M. Sauer, Commun. Biol. 2019, 2, 261.

[47] N. K. Devaraj, S. Hilderbrand, R. Upadhyay, R. Mazitschek, R. Weissleder, Angew. Chemie Int. Ed. 2010, 49, 2869-2872.

[48] J. C. T. Carlson, L. G. Meimetis, S. A. Hilderbrand, R. Weissleder, Angew. Chemie Int. Ed. 2013, 52, 69176920.

[49] A. J. C. Sarris, T. Hansen, M. A. R. de Geus, E. Maurits, W. Doelman, H. S. Overkleeft, J. D. C. Codée, D. V Filippov, S. I. van Kasteren, Chem. - A Eur. J. 2018, 24, 18075-18081.

[50] G. Linden, L. Zhang, F. Pieck, U. Linne, D. Kosenkov, R. Tonner, O. Vázquez, Angew. Chemie Int. Ed. 2019, 58, 12868-12873. 
[51] M. R. Karver, R. Weissleder, S. A. Hilderbrand, Bioconjug. Chem. 2011, 22, 2263-2270.

[52] Z. Shen, G. Reznikoff, G. Dranoff, K. L. Rock, J. Immunol. 1997, 158, 2723 LP - 2730.

[53] T. van Leeuwen, C. Araman, L. Pieper Pournara, A. S. B. Kampstra, T. Bakkum, M. H. S. Marqvorsen, C. R. Nascimento, G. J. M. Groenewold, W. van der Wulp, M. G. M. Camps, G. M. C. Janssen, P. A. van Veelen, G. J. P. van Westen, A. P. A. Janssen, B. I. Florea, H. S. Overkleeft, F. A. Ossendorp, R. E. M. Toes, S. I. van Kasteren, RSC Chem. Biol. 2021, 2, 855-862.

[54] T. J. Grevengoed, E. L. Klett, R. A. Coleman, Annu. Rev. Nutr. 2014, 34, 1-30.

[55] D. Casares, P. V Escribá, C. A. Rosselló, Int. J. Mol. Sci. 2019, 20.

[56] C. Moessinger, K. Klizaite, A. Steinhagen, J. Philippou-Massier, A. Shevchenko, M. Hoch, C. S. Ejsing, C. Thiele, BMC Cell Biol. 2014, 15, 43.

[57] M. L. W. J. Smeenk, J. Agramunt, K. M. Bonger, Curr. Opin. Chem. Biol. 2021, 60, 79-88.

[58] F. Chehrehasa, A. C. B. Meedeniya, P. Dwyer, G. Abrahamsen, A. Mackay-Sim, J. Neurosci. Methods 2009, 177, 122-130.

[59] N. T. Castellucci, C. E. Griffin, J. Am. Chem. Soc. 1960, 82, 4107.

[60] L. S. Silbert, J. Am. Oil Chem. Soc. 1984, 61, 1090-1092.

[61] R. Peláez, A. Pariente, Á. Pérez-Sala, I. M. Larráyoz, Cells 2020, 9. 